\title{
The Problem of Massive Deception for Justification Norms of Action
}

\author{
Arturs Logins
}

Received: 5 February 2013 / Accepted: 23 December 2013 / Published online: 1 May 2014

(C) Springer Science+Business Media Dordrecht 2014

\begin{abstract}
In this paper, I argue against recent versions of justification norms of action and practical deliberation (Neta, Noûs 43:684-699, 2009; Gerken, Synthese 178:529547, 2011, Synthese 189:373-394, 2012; Smithies, Noûs 46:265-288, 2012). I demonstrate that these norms yield unacceptable results in deception cases. However, a further modification of justification norms in the light of these results appears to be ad hoc. Hence, I claim, we should reject justification norms of action and practical deliberation.
\end{abstract}

Keywords Knowledge $\cdot$ Justification $\cdot$ Action $\cdot$ Practical deliberation · Norms

\section{Introduction}

Presumably everyone will agree that rationality of an action and of a practical deliberation depends in part on some epistemic constraints. Divisions start when it comes to describe what exactly such constraints amount to. Traditionally, such constraints have been determined in the framework of (subjective) Bayesian decision theory. Recent developments in epistemology, however, have opened up new perspectives for this debate. In particular, it has been claimed, contra the traditional (subjective) Bayesian approach, that the epistemic constraint on rational action and practical deliberation is knowledge (knowledge norms of action and practical deliberation). ${ }^{1}$

One such innovative formulation of a knowledge norm of practical deliberation is the following one:

\footnotetext{
${ }^{1}$ See, for instance, Unger (1975), Hyman (1999), Hawthorne and Stanley (2008), Stanley (2005) and Hawthorne (2004). See Ichikawa (2012) for an overview.

A. Logins

Département de philosophie, Université de Genève, Rue de Candolle 2, 1205 Genève, Switzerland e-mail: Arturs.Logins@unige.ch
} 
Knowledge-Reasons Principle (KRP) Where subject S's choice is $p$ dependent, ${ }^{2}$ it is appropriate (=rationally permitted) for $\mathrm{S}$ to treat the proposition that $p$ as a reason for acting if and only if $\mathrm{S}$ knows that $p$ (cf. Hawthorne and Stanley 2008, p. 578).

On the other side, it has been objected that there are a lot of counterexamples for such knowledge norms. In Gettier cases for instance, the subject has a justified true belief that seems to provide the needed epistemic ingredient for rational action and deliberation. And similarly in some cases where the subject has all the justification needed for a given belief but that belief is - unbeknownst to her-false. ${ }^{3}$ In the light of these objections to the knowledge norm, many philosophers have endorsed one or another version of justification norm, that is, one or another version of norm which identifies necessary and sufficient epistemic conditions for rational action and practical deliberation with justified belief rather than knowledge. ${ }^{4}$

In this paper, however, I show that justification norms deliver unacceptable results when we consider possible deception scenarios. Namely, cases of radical deception where a person is epistemicaly justified in believing that $\mathrm{p}$ without even having in principle a possibility to act or deliberate on $\mathrm{p}$. Such counterexamples, I argue, should motivate us to abandon justification norms of action and practical deliberation since they show that justification is not sufficient for rational action/deliberation. I do not pretend, however, to provide an ultimate, knockdown reason to accept a knowledge norm such as KRP or other. Nevertheless, if one can provide a plausible explanation of the lack of rationality of action or of practical deliberation in Gettier and false belief cases, then my argument supports the knowledge norm. ${ }^{5}$ Such task however is beyond the scope of the present paper.

In what follows, I first examine justification norms of action and practical deliberation in more detail. I then provide arguments against justification norms of action and practical deliberation and consider some possible objections against them.

\footnotetext{
2"Let us say that a choice between options $x_{1} \ldots x_{n}$ is $p$ dependent if the most preferable of $x_{1} \ldots x_{n}$ conditional on the proposition that $p$ is not the same as the most preferable of $x_{1} \ldots x_{n}$ conditional on the proposition that not-p." (Hawthorne-and-Stanley 2008, p. 578).

${ }^{3}$ For counterexamples and arguments against the knowledge norm, see Brown (2008), Neta (2009), Littlejohn (2009a), Gerken (2011) and Smithies (2012).

${ }^{4}$ See, for example, Neta (2009); Gerken (2011, 2012, 2013, 2014), Smithies (2012) and Smith (2012). See also Gibbons (2010) and Littlejohn (2009b) for an overview.

${ }^{5}$ The proponents of knowledge norm have argued that in some controversial cases (i.e. false belief cases where we tend to judge that the subject's action or deliberation that is based on the falsely believed proposition is still rational) a subject is excused for acting/deliberating on $p$, even though her action/deliberation is not fully rational (see, for example, Hawthorne and Stanley 2008). The main idea is to concede that in such cases the subject's acting/deliberating on $p$ is not as bad (irrational) as in cases where she has no excuses for her acting/deliberating on ignorance. This strategy has, however, been strongly criticized by the opponents of knowledge norm (see, for example, Gerken 2011; Smithies 2012). The main objection against it is that there is nothing to be excused in such cases, hence this line of defence is ad hoc. A more complete defence of knowledge norm should address this criticism in details.
} 


\section{Justification Norms}

Before I proceed to arguments, let us consider in more detail justification norms of action and practical deliberation.

Here are three contemporary statements of justification norms. As I take them as typical statements of justification norms, I will concentrate exclusively on them in the rest of my paper:

$J B K$-Reasons Principle (JBKRP) Where subject $S$ 's choice is $p$ dependent, it is rationally permissible for $S$ to treat the proposition that $p$ as a reason for acting if and only if $S$ justifiably believes that she knows that $p$ (cf. Neta 2009, p. 686). ${ }^{6}$

The JK Rule One has justification to assert and to act on $\mathrm{P}$ if and only if one has justification to believe that one is in a position to know that P (cf. Smithies 2012, p. 270). ${ }^{7,8}$

WA "In the deliberative context, DC, S meets the epistemic conditions on rational use of (her belief that) $p$ as a premise in practical reasoning or of (her belief that) $p$ as a reason for acting (if and) only if $\mathrm{S}$ is warranted in believing that $\mathrm{p}$ to a degree that is adequate relative to DC" (Gerken 2011, p. 530; see also Gerken 2012, 2013, 2014).

First, here are some terminological remarks. The quasi-technical term "warrant" is coined to subsume both the property that internalists have called "justification",

\footnotetext{
${ }^{6} \mathrm{JBKRP}$ is a justification norm of a restricted kind since it specifies that only justified beliefs about one's knowledge (a type of higher-order beliefs) constitute the relevant epistemic constraint on treating $\mathrm{p}$ as a reason for action. But as it relies on justified belief (even if it is only a certain type of justified belief), it is still a version of a justification norm.

${ }^{7}$ The JK rule also restricts justification to assert and to act on $\mathrm{P}$ to a certain type of higher-order justification to believe. Hence, we can observe that despite their differences, the JK rule and the JBKRP are similar in this significant aspect: both state a requirement in terms of higher-order justification. Now, this higherorder requirement itself faces a certain kind of objection, namely, the objection of over-intellectualization. More specifically, it can be objected that, counterintuitively, the JK rule and the JBKRP seem to imply that children and animals (i.e. agents who do not possess higher-order beliefs) cannot treat a proposition as a reason for acting in a rationally permissible way (the JBKRP) or cannot have justification to assert and to act on $\mathrm{P}$ (the JK rule). Smithies responds to a similar challenge against his account of justification to believe in Smithies (2014). A congenial line of defence here would be to insist that the objection of over-intellectuaization does not raise a problem for the JK rule since the JK rule appeals to propositional rather than to doxastic justification. The problem of over-intellectualization is a potential problem only to views about doxastic justification (see Smithies (2014)). Neta for his part, might avoid the problem in a different way. His norm, the JBKRP, concerns higher-order practical deliberation (as we will clarify it in a while). It is not unreasonable to suppose that animals and children do not engage in higher-order practical deliberation. Hence, as long, as one is willing to restrict higher-order practical deliberation in this way (i.e. not ascribing it to children and animals), one can also maintain that the objection of over-intelectualization does not have a bite on the JBKRP. Thanks to an anonymous referee for this journal here.

${ }^{8} \mathrm{Here}$, I will focus on action in general, leaving aside a more specific question about epistemic norms of assertion. However, see "Conclusion", where I indicate how a similar problem might affect justification norms of assertion.
} 
and the property that (some) externalists have called "entitlement". In short, "justification" and "entitlement" are supposed to be two species of one genus- "warrant". 9

Concerning "deliberative context, DC" (in WA), I follow Gerken in considering it as corresponding to the description of a given situation from a subject's perspective. For my purposes, it is important to note only that Gerken explains deliberative context in terms of one's rational presuppositions about circumstances one is in (cf. Gerken 2011, p. 530, fn.2). Another way to put it might be-rational background beliefs about circumstances one is in. Independently from the issue whether a presupposition is a state of doxastic kind, or of some other kind, it is important to notice that a presupposition is surely not a factive state, i.e. it does not entail the truth of its content.

Another point that needs explanation is why WA leaves the left-to-right direction in a parenthesis. According to Gerken, it indicates that the sufficiency of WA constraints for a rational action/deliberation depends on further specifications of notions employed in WA. Notably, it depends on the specification of what exactly constitutes deliberative context (cf. Gerken 2011, p. 531). Again, for my purposes it is important just to notice that this sufficiency is determined by aspects of the subject's perspective-her presuppositions/beliefs and her psychological basis for action. Gerken gives a list of some parameters that (partly) constitute one's deliberative context: (i) one's rational presuppositions (/background beliefs) about alternative courses of action, (ii) one's rational presuppositions (/background beliefs) about the availability of further evidence, (iii) one's rational presuppositions (/background beliefs) about urgency and (iv) one's rational presuppositions (/background beliefs) about the stakes associated with the action (cf. Gerken 2011, p. 531).

One more important point to specify is that of course for an action or a practical deliberation to be overall rational, there are more than epistemic constraints. As many have noticed (see, for example, Gerken 2011; Smithies 2012), there are cases where a practical deliberation is rational from the epistemic point of view but not "overall" (all-things-considered) rational. For example, it might be rational from the epistemic point of view to proceed to more clinical trials before authorizing a vaccine against a rapidly spreading mortal virus but not rational from the overall rationality point of view.

We should also specify what the justification norms are a little more exactly since they seem to use different formulations of action and practical deliberation.

\footnotetext{
${ }^{9}$ See Gerken (2011), p. 530; Gerken (2013): 3 and Gerken (2012), p. 374, fn.1, where he states that he uses "warrant" as a genus for internalist and externalist justification. Gerken follows Burge (2003) for this terminology and dissociates it from Plantinga's and Wright's uses of "warrant". Gerken also notices that Hawthorne and Stanley (2008) have used the term "justification" in a similar sense to Burge's "warrant" (Gerken 2011, p. 530, see also Gerken 2012, p. 381-386 for a more detailed characterisation of "warrant" and "justification"). The problem with the term "warrant" as used by Gerken, however, is that it cannot subsume all externalist and internalist uses of "justification" or "entitlement". For Gerken states that "[t]he term ["warrant"] is non-factive", (Gerken 2011, p. 530). This seems to be incompatible with at least some versions of externalist views according to which justification is factive, for recent examples, see Sutton (2007) and Littlejohn (2012). In what follows, I will not pursue this consideration further. I will assume for the sake of argument on Gerken's sense of "warrant" - a genus term for non-factive justification and entitlement, where to say that a warranted belief is non-factive means that it does not entail the truth of its content. Thanks to an anonymous referee for this journal for suggesting to clarify the notion of "warrant" as used by Gerken.
} 
JBKRP states its object in the following way: "[..] it is rationally permissible for $S$ to treat the proposition that $p$ as a reason for acting if and only if [..]", whereas WA states "[..]S meets the epistemic conditions on rational use of (her belief that) $p$ as a premise in practical reasoning or of (her belief that) $\mathrm{p}$ as a reason for acting (if and) only if [..]". And the JK rule states "One has justification to [..] act on P if and only if [..]". JBKRP is about treating $p$ as a reason for action, whereas WA is about using $p$ in one's practical reasoning and about using $p$ as a reason for acting. And the $\mathrm{JK}$ rule is about acting on $P$. Furthermore, KRP is also stated in terms of treating $p$ as a reason for action. In order to clarify this terminological issue, I follow Gerken and assume that Neta's use of "treating $\mathrm{p}$ as a reason for acting" concerns a kind of practical deliberation that involves higher-order metacognitive capacities, whereas Hawthorne and Stanley's use does not, as neither does Gerken's. ${ }^{10}$ I also assume that to act on $P$ (in the $\mathrm{JK}$ rule) is the same as using $p$ as a reason for acting (in the WA).

In the light of these clarifications, I propose then to distinguish the following categories:

Rational Action S's action $\phi$ is rational $=$ in her $\phi$-ing, S makes rational use of a (relevant) proposition $\mathrm{p}$ as a reason for $\phi$-ing.

For example, to say that Maria's action of taking an umbrella is rational just means that her use of the relevant proposition, say, that it is raining outside, as a reason for taking the umbrella is rational. In short, an action is rational when it relies on a reason in a rational way. The necessary and sufficient conditions for such rational reliance on a relevant proposition are fixed by knowledge or justification norms.

Rational Practical Reasoning S's practical reasoning is rational $=\mathrm{S}$ makes rational use of a (relevant) proposition $\mathrm{p}$ as a premiss in her practical reasoning.

For example, to say that Maria's practical reasoning is rational just means that Maria's use of the relevant proposition, say, that an umbrella is too cumbersome for taking it with her to the cinema in her practical reasoning is rational.

Rational Treating $p$ as a Reason for Action S's treating $p$ as a reason for action $\phi$ is rational = either (1) in the first-order sense: (a) In her $\phi$-ing ,S makes rational use of a (relevant) proposition $\mathrm{p}$ as a reason for $\phi$-ing [rational action], or (b) $S$ makes rational use of a (relevant) proposition $p$ as a premiss in her practical reasoning

\footnotetext{
10“'To assess Neta's discussion, it is crucial to note that he changes the topic. His account concerns S's 'treating $\mathrm{p}$ as a reason' in the higher-order sense of S's conceiving herself as having $\mathrm{p}$ as a reason. In contrast, (WA) as well as Hawthorne and Stanley's knowledge account are concerned with 'treating p as a reason' in the first-order sense of using or relying on (the belief that) p. So, Neta does not address the issue that Hawthorne, Stanley and I are concerned with" (Gerken 2011, p. 535, fn.9 (original italics)).
} 
[rational practical reasoning]; OR (2) in the higher-order sense: $\mathrm{S}$ is rationally conceiving herself as having $\mathrm{p}$ as a reason for action [Neta's sense].

The last description illustrates that treating $p$ as a reason for action can be used in multiple senses. It seems then that "treating" is a rather ambiguous term since one can be said to treat $\mathrm{p}$ as a reason for action, when $\mathrm{S}$ effectively acts relying on $\mathrm{p}$ (think of Maria taking her umbrella while effectively relying on the proposition that it is raining outside); in other situations, however, $\mathrm{S}$ can be characterized as treating $\mathrm{p}$ as a reason for action when $\mathrm{S}$ uses $\mathrm{p}$ as a premiss in her practical reasoning (when Maria considers in her practical reasoning the proposition that the umbrella is too cumbersome). And still in other situations, one can also use " $S$ 's treating $\mathrm{p}$ as a reason for action" while referring to S's conceiving of herself as having a reason for that action (when Maria conceives herself as having a reason for going to the hospital, namely, that she has symptoms of an illness, despite that it is raining outside and she does not have an umbrella). At least it does not seem obvious that our use of "treating something as a reason for action" is only the higher-order sense.

Furthermore, WA and KRP use the first-order sense of "treating $\mathrm{p}$ as a reason for action" (1), where Neta's JBKRP refers to the higher-order sense (2).

In order to improve clarity, I propose to reserve the term "practical deliberation" for practical reasoning and "higher order practical deliberation" for the (2) sense of "treating $\mathrm{p}$ as a reason for action" (that is the sense in which Neta uses "treating $\mathrm{p}$ as a reason for acting").

My aim in this paper is to show that justification is not an adequate norm for rational action, nor practical deliberation, nor higher-order practical deliberation.

\section{Action and Deception}

My claim is that the above justification-based norms do not have the resources to resist the conclusion that it is possible for a subject $S$ to be at the same time justified in believing that $\mathrm{p}$ (to an adequate degree relative to a deliberative context), or justified in believing that she knows that $\mathrm{p}$, and at the same time to lack rationality of action, rationality of practical deliberation or rationality of higher-order practical deliberation. To this end, I will present some cases in which a subject is deceived, and hence cannot act, but should be considered by the proponents of the justification norms as justified in believing $\mathrm{p}$ to a degree that is adequate relative to the deliberative context.

The Problem of Deception Consider the following thought experiment. Maria and Maria's mental duplicate Maria*, a deceived brain in a vat, share the same non-factive mental states and are both careful reasoners. Maria and Maria* differ, however, with respect to the truth value of their beliefs and other non-factive states. Where Maria happens to have true beliefs, Maria* has no (or almost no) true beliefs. Traditionally, this thought experiment (known also as the New Evil Demon scenario) is largely taken to demonstrate that if we take that Maria's belief that $p$ is justified, then we should also accept that Maria's* belief that $\mathrm{p}$ is justified since it seems 
counterintuitive to claim the contrary. ${ }^{11}$ Without entering into a further discussion about whether this scenario disqualifies certain conceptions of justification, let us just accept for the sake of argument that Maria and Maria* are both justified in believing a certain proposition $\mathrm{p}$ to a degree that is adequate to the deliberative context of Maria and Maria*. ${ }^{12}$ Given that the deliberative context is specified on the basis of non-factive mental states, and Maria and Maria* are mental duplicates, it follows that Maria and Maria* share the same deliberative context (in short, the New Evil Demon scenario can be applied also to motivate the equal rationality of presuppositions that constitute the deliberative context). Let us also presuppose that the deliberative context for Maria in this scenario is appropriate for the sufficiency condition of WA to apply. In other words, the deliberative context DC, for Maria, is such that if Maria is justified in believing that $\mathrm{p}$ to a degree that is adequate relative to the deliberative context DC, then Maria meets the epistemic conditions on rational use of $\mathrm{p}$ as a reason for action.

Now, as Maria is justified in believing that $\mathrm{p}$ to a degree that is adequate relative to DC (as presupposed in the example), it follows (from WA) that Maria meets the epistemic conditions on rational use of $\mathrm{p}$ as a reason for acting. And crucially, from our thought experiment, it follows then that Maria* also meets the epistemic conditions on rational use of $\mathrm{p}$ as a reason for acting in this case since Maria and Maria* are justified in believing $\mathrm{p}$ to the same degree, and Maria and Maria* are in identical deliberative contexts.

However, as Maria* is a brain in a vat, she cannot perform any actions (or she can perform very few actions). But if an action cannot ever be realized, then it is not the case that it can be rational. Since rationality (if we speak about epistemic conditions on practical rationality) is a property that only an action can possess or not possess. That is, in the terminology of WA, if an action cannot in principle be realized, then a subject could never meet the epistemic conditions on the rational use of a reason for that action. Indeed, it seems at least odd to say that an action cannot be realizable but it is still reasonably permitted. Therefore, we can conclude that Maria* does not meet the epistemic conditions on rational use of $\mathrm{p}$ as a reason for acting in our scenario. But

\footnotetext{
${ }^{11}$ The New Evil Demon thought experiment was introduced into contemporary epistemology by Lehrer and Cohen (1983) and Cohen (1984). It is widely accepted, by both internalists (as for example, Lehrer and Cohen 1983; Cohen 1984; Wedgwood 2002) and externalists (as Goldman 1986; Burge 2003; Comesana 2002), that the subject and her deceived counterpart are both justified (or warranted). The thought experiment constitutes a problem for any externalist account of justification (warrant) because it appears to demonstrate that it is possible for a subject to have epistemic justification for believing without satisfying any externalist criteria for justification (it is supposed, for instance, that a deceived counterpart's belief forming process is not reliable). There have been an impressive number of externalist attempts to deal with this major problem (for some paradigmatic examples see, Goldman 1986; Bach 1985; Mylan Engel 1992; Williamson 2000; Littlejohn 2009a, b; Weatherson 2008; Henderson et al. 2007; Comesana 2002, 2005; Graham 2012). In what follows, we will not, however, enter into that debate. Thanks to an anonymous referee for this journal here.

${ }^{12}$ If one is willing to deny the sameness of justification in the deception case, then my argument does not manage to establish its conclusion. However, it is also reasonable to assume that those who are willing to endorse justification norms of action are also willing to accept that brains in a vat can have justified beliefs. This seems, for instance, to be the case with Smithies. For he defends an internalist conception of justification for believing, see Smithies (2014).
} 
this is clearly in contradiction with our previous conclusion. This is an unacceptable result. We can state the argument in a more formal manner:

Argument from deception against the justification norm of action

(1.1) WA norm [Assumption]

(1.2) $\mathrm{S}$, a brain in a vat, is justified in believing that $\mathrm{p}$ to a degree that is adequate relative to her deliberative context, DC [BIV scenario].

(1.3) In the appropriate deliberative context DC, S meets the epistemic conditions on rational use of $\mathrm{p}$ as a reason for acting [WA, 1.2].

(1.4) However, if a subject cannot realize any action, then the subject does not meet the epistemic conditions on rational use of $\mathrm{p}$ as a reason for acting [rationality of action implies the possibility to perform action].

(1.5) And crucially, in a BIV scenario, subject $S$ cannot realize any action [BIV scenario].

(1.6) Therefore, in the deliberative context DC, S does not meet the epistemic conditions on rational use of $\mathrm{p}$ as a reason for acting $[1.4,1.5]$.

Premisses $1.1-1.5$ are mutually inconsistent and lead to absurdity. In order to avoid the contradiction, I suggest we reject the WA principle. ${ }^{13}$

Some might object to my argument by saying that the constraint on the realizability of action can be included in the WA principle, as a part of DC or as an additional condition for a rational action.

To such an objection, I respond that this might turn out to be either a too strong or an ad hoc constraint. First, including it in the specification of the deliberative context would be too strong for it would assimilate the deliberative context to the de facto circumstances in which a subject happens to be, which is contrary to what Gerken has claimed (see Gerken 2011, p. 530, fn.2). As we have seen, one's deliberative context is taken to consist of one's rational presuppositions about what circumstances one is in. Second, if we include the realizability of an action as another condition (in addition to justified belief) for (epistemic) constraints on rational action in the

\footnotetext{
${ }^{13}$ This argument can be easily adapted also to work against the JK rule, which is another justification norm of action. Here is one way how it can be adapted against the JK rule:

(1.1') The JK rule [Assumption]

(1.2') $\mathrm{S}$, a brain in a vat, is justified in believing that she is in a position to know $\mathrm{p}$ [BIV scenario].

(1.3') $\mathrm{S}$ has justification to act on $\mathrm{P}(=\mathrm{S}$ meets epistemic conditions on rational use of $\mathrm{p}$ as a reason for acting [the JK rule, 1.2'].

(1.4') However, if a subject cannot realize any action, then the subject does not meet the epistemic conditions on rational use of $\mathrm{p}$ as a reason for acting (= has no justification to act on $\mathrm{p}$ ) [rationality of action implies the possibility to perform action].

(1.5') And crucially, in a BIV scenario, subject S cannot realize any action [BIV scenario].

(1.6') Therefore, $\mathrm{S}$ does not meet the epistemic conditions on rational use of $\mathrm{p}$ as a reason for acting $\left[1.4^{\prime}, 1.5^{\prime}\right]$.
}

Premisses 1.1 ' -1.5 ' are mutually inconsistent and lead to absurdity. To avoid the contradiction, I advocate the rejection of the $\mathrm{JK}$ rule. 
WA, we need an independent motivation for that. That is, if one modifies the right part of the WA by adding to " $\mathrm{S}$ is warranted in believing that $\mathrm{p}$ to a degree that is adequate relative to DC" a clause "AND S can perform actions", then one needs to show that such a clause is not here only in order to avoid BIV cases. A more motivated explanation would need to be given. In absence of such a motivation, it seems to me that such a move should be classified as ad hoc.

Notice also that contrary to WA, a knowledge norm of action does not imply such unacceptable results. By the sole fact that knowledge is factive and incompatible with deception scenarios (brains in a vat do not have knowledge), any cases where action is not possible is excluded.

A similar argument can be made against the justification norm of practical deliberation.

\section{Argument from deception against the justification norm of practical deliberation}

(2.1) WA norm [Assumption]

(2.2) $\mathrm{S}$, a brain in a vat, is justified in believing that $\mathrm{p}$ to a degree that is adequate relative to her deliberative context, DC [BIV scenario].

(2.3) In the appropriate deliberative context DC, S meets the epistemic conditions on rational use of $\mathrm{p}$ as a premiss in practical reasoning [WA, 2.2].

(2.4) However, if a subject cannot realize any action, then the subject does not meet the epistemic conditions on rational use of $\mathrm{p}$ as a premiss in practical reasoning [practical deliberation implies realizability of action]

(2.5) And crucially, in a BIV scenario, subject $\mathrm{S}$ cannot realize any action [BIV scenario].

(2.6) Therefore, in the deliberative context DC, S does not meet the epistemic conditions on rational use of $\mathrm{p}$ as a premiss in practical reasoning [2.4, 2.5].

Premisses $2.1-2.5$ are mutually inconsistent and lead to absurdity. I suggest we reject WA.

It can be argued against my second argument that it is not true that practical deliberation implies the realizability of action. Even in BIV cases, it is clear that subjects do reason. Hence, it seem too strong to claim that all practical reasoning end in action.

To this I reply that, it is true that even in BIV cases, subjects do reason. But to reason is not exactly the same thing as practical reasoning. If subjects in BIV cases reason, their reasoning remains theoretical. If their reasoning never ends in action, then I do not see how it differs from theoretical reasoning. The difference between theoretical and practical reasoning, as I see it, is not just a difference in the content of the premisses that we use in them. Theoretical reasoning has as its constitutive end a state of belief or conviction, whereas practical reasoning has as its constitutive end an action or at least intention to act. And that is how we ordinarily proceed: our theoretical reasoning normally ends in states of believing, whereas our practical reasoning normally ends in action or at least intention to act. 
Similar suggestions come from a recent work on practical deliberation in practical philosophy:

"Determining what to think or what to do is thus a constitutive end of deliberation, in the same way that persuasion is a constitutive end of arguing, or getting coffee is a constitutive end of going for coffee. Deliberation can fail to achieve its end, but it is an activity that aims to achieve that end (perhaps among others)" (Arpaly and Schroeder 2012, p. 211).

And finally, a similar argument can be made also against higher-order practical deliberation:

Argument from deception against the justification norm of higher-order practical deliberation

(3.1) JBKRP norm [Assumption]

(3.2) In a situation where S's choice is p dependent, $S$, a brain in a vat, is justified in believing that she knows that $\mathrm{p}$ [BIV scenario].

(3.3) It is rationally permissible for $\mathrm{S}$ to treat the proposition $\mathrm{p}$ as a reason for acting [JBKRP, 3.2].

(3.4) However, if a subject cannot realize any action, then it cannot be rationally permissible for a subject to treat the proposition $\mathrm{p}$ as a reason for acting [higher-order practical deliberation implies the realizability of action].

(3.5) And crucially, in a BIV scenario, subject $S$ cannot realize any action [BIV scenario].

(3.6) Therefore, it is not rationally permissible for $\mathrm{S}$ to treat the proposition $\mathrm{p}$ as a reason for acting $[3.4,3.5]$.

Premises $3.1-3.5$ are mutually inconsistent and lead to absurdity. I suggest that we reject JBKRP.

Here, the matters might appear a little bit more controversial. If in the two preceding arguments it might have seen more plausible to consider that realizability implies action, or practical deliberation, then it might seemed less plausible in the case of conceiving oneself as having a reason for acting.

However, the reason why I maintain the idea that even higher-order practical deliberation implies the realizability of action is the following. It seems implausible that in a case where a subject can never act for a reason (a BIV scenario), she can nevertheless conceive herself as having a reason for action in the sense that is of interest in the present discussion. I take it that conceiving oneself as having a reason for acting is not just a second-order belief about justifiably believing a proposition. It is still a state that typically ends in an action or in an intention. The difference with first-order practical deliberation is that here a subject is aware of the reason that she has for her action, what is not necessary for the deliberation in the first-order sense (see also Arpaly and Schroeder 2012). Therefore, I conclude that higher-order practical deliberation implies the realizability of action, just as for first-order practical deliberation. 


\section{Conclusion}

In this paper, I have argued against justification norms of action, practical deliberation and higher-order practical deliberation. My claim is that there is nothing in justified belief in any proposition $\mathrm{p}$ (to a degree adequate relative to given deliberative context) that may ensure the rational use of $\mathrm{p}$ as a reason for action, or use of $\mathrm{p}$ as a premise in one's practical reasoning, or conceiving oneself as having $\mathrm{p}$ as a reason for action.

An additional upshot of my paper is that it might be possible to develop a similar argument against a justification norm of assertion (as the norm proposed by Smithies (2012) or Gerken's recent proposal in Gerken (2014), for instance). ${ }^{14}$ Smithies' norm of justification is an epistemic norm of both practical deliberation and assertion. Gerken has recently endorsed a view according to which his WA norm of action is structurally similar to the norm of assertion (Gerken 2014). Moreover, there has been recently an increasing amount of interest among epistemologists in the question of whether the norm of action (and practical deliberation) and assertion is the same (see for instance Brown 2012; Montminy 2013; McKinnon 2012; McKenna 2013). Anyone who thinks that these norms are the same and justification based for both action (practical deliberation) and assertion will meet the same kind of problem that I have developed here against justification norms of action, practical deliberation and higher-order practical deliberation. For assertion, like action and practical deliberation, cannot be performed in deception scenarios. It seems reasonable to suppose that brains in vats do not assert anything. Some of the (typical) preconditions for asserting cannot ever be met in BIV scenarios. BIVs cannot physically assert (BIVs cannot speak because they do not have mouths and they cannot use a sign language because they do not have hands), and more importantly, there is no audience in a BIV scenario. It seems reasonable to suppose that without audience, there is no assertion (except some special cases). ${ }^{15}$ However, BIVs do have justified beliefs (at least if one is internalist, one should be sensible to the possibility of justified false beliefs). Therefore, we can generate the same type of argument from deception cases against justification based norms of assertion, as we have done against justification norms of action, practical deliberation and practical higher-order deliberation.

I conclude then that given the failure of justification norms in certain possible scenarios, there seem to be only two possible further options: either it is impossible to provide a specific epistemic norm of action, deliberation and higher-order deliberation (and assertion), or a kind of knowledge norm of these is true. I hope that the state of the matter is not so pessimistic as to oblige us to adopt the first one.

Acknowledgments Thanks to Santiago Echeverri, Robin McKenna and an anonymous referee for this journal for useful comments and discussion. The research work that lead to this article was supported by the Swiss National Science Foundation (SNSF) grant number 100015_131794 (project "Knowledge, Evidence, and Practice").

\footnotetext{
${ }^{14}$ Thanks to an anonymous referee for this journal and to Robin McKenna here

${ }^{15}$ Gerken seems to endorse the idea that there should be an audience for an act to be an act of assertion: "Assertions are, at least typically, uttered in conversations (broadly construed) and they do, at least typically, have an audience (broadly construed)" (Gerken 2012, p. 378).
} 


\section{References}

Arpaly, N., \& Schroeder, T. (2012). Deliberation and acting for reasons. Philosophical Review, 121(2), 209-239.

Bach, K. (1985). A rationale for reliabilism. The Monist, 68(2), 246-263.

Brown, J. (2008). Knowledge and practical reason. Philosophy Compass, 3(6), 1135-1152.

Brown, J. (2012). Assertion and practical reasoning: common or divergent epistemic standards? Philosophy and Phenomenological Research, 84(1), 123-157.

Burge, T. (2003). Perceptual entitlement. Philosophy and Phenomenological Research, 67(3), 503-548.

Cohen, S. (1984). Justification and truth. Philosophical Studies, 46(3), 279-95.

Comesaña, J. (2002). The diagonal and the demon. Philosophical Studies, 110(3), 249-266.

Comesaña, J. (2005). We are (almost) all externalists now. Philosophical Perspectives, 19(1), 59-76.

Engel, M. (1992). Personal and doxastic justification in epistemology. Philosophical Studies, 67(2), 133150 .

Gerken, M. (2011). Warrant and action. Synthese, 178(3), 529-547.

Gerken, M. (2012). Discursive justification and skepticism. Synthese, 189(2), 373-394.

Gerken, M. (2013). The roles of knowledge ascriptions in epistemic assessment. European Journal of Philosophy. doi:10.1111/ejop.12026.

Gerken, M. (2014). Same, same but different: the epistemic norms of assertion, action and practical reasoning. Philosophical Studies, 168(3), 725-744.

Gibbons, J. (2010). Things that make things reasonable. Philosophy and Phenomenological Research, $81(2), 335-361$.

Goldman, A. I. (1986). Epistemology and cognition. Harvard University Press.

Graham, P. J. (2012). Epistemic entitlement. Nô̂s, 46(3), 449-482.

Hawthorne, J. (2004). Knowledge and lotteries. Oxford University Press.

Hawthorne, J., \& Stanley, J. (2008). Knowledge and action. Journal of Philosophy, 105(10), 571-590.

Hyman, J. (1999). How knowledge works. Philosophical Quarterly, 50(197), 433-451.

Ichikawa, J. J. (2012). Knowledge norms and acting well. Thought, 1(1), 49-55.

Lehrer, K., \& Cohen, S. (1983). Justification, truth, and coherence. Synthese, 55(2), 191-207.

Littlejohn, C. (2009a). Must we act only on what we know? Journal of Philosophy, 106(8), 463-473.

Littlejohn, C. (2009b). On treating something as a reason for action. Journal of Ethics and Social Philosophy, 4(1), 1-4.

Littlejohn, C. (2012). Justification and the truth-connection. Cambridge University Press.

McKenna, R. (2013). Why assertion and practical reasoning are possibly not governed by the same epistemic norm. Logos and Episteme, 4(4), 457-464.

McKinnon, R. (2012). What I learned in the lunch room about assertion and practical reasoning. Logos and Episteme, 3(4), 565-569.

Montminy, M. (2013). Why assertion and practical reasoning must be governed by the same epistemic norm. Pacific Philosophical Quarterly, 94(1), 57-68.

Neta, R. (2009). Treating something as a reason for action. Noûs, 43(4), 684-699.

Smith, M. (2012). Some thoughts on the JK-rule. Noûs, 46(4), 791-802.

Smithies, D. (2012). The normative role of knowledge. Noûs, 46(2), 265-288.

Smithies, D. (2014). Why justification matters. In D. Henderson \& J. Greco (Eds.), Epistemic evaluation: point and purpose in epistemology. Oxford University Press, in press.

Stanley, J. (2005). Knowledge and practical interests. Oxford University Press.

Sutton, J. (2007). Without justification. MIT Press.

Henderson, D., Horgan, T., Potrč, M. (2007). Transglobal evidentialism-reliabilism. Acta Analytica, 22(4), 281-300.

Unger, P. K. (1975). Ignorance: a case for scepticism. Oxford University Press.

Weatherson, B. (2008). Deontology and descartes's demon. Journal of Philosophy, 105(9), 540-569.

Wedgwood, R. (2002). Internalism explained. Philosophy and Phenomenological Research, 65(2), 349369.

Williamson, T. (2000). Knowledge and its limits. Oxford University Press. 